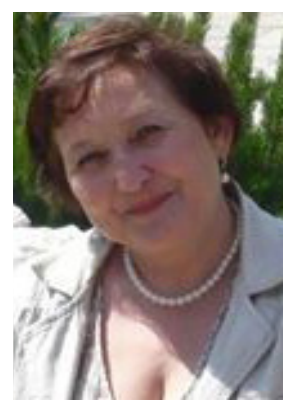

Шарипова И.М.

Sharipova I.M.

кандидат экономических наук, доиент кафедры «Проектный менеджмент и экономика предпринимательства», ФГБОУ ВО «Уфимский государственный нефтяной технический университет»,

2. Уфа, Российская Федераџия

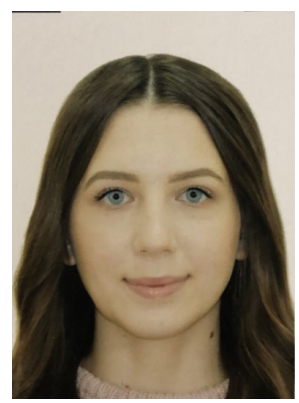

Вьюгова Д.С. Vyugova D.S.

студент кафедры «Проектный менеджмент и экономика предпринимательства», ФГБОУ ВО «Уфимский государственный нефтяной технический университет»,

2. Уфа, Российская Федерация

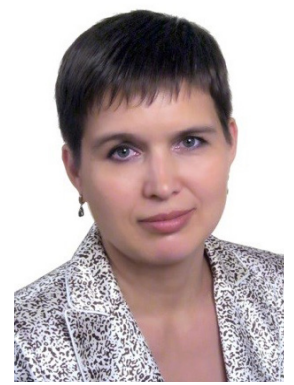

Сунаева Г.Г.

Sunaeva G.G.

кандидат экономических наук, доиент кафедры «Проектный менеджмент и экономика предпринимательства», ФГБОУ ВО «Уфимский государственный нефтяной технический университет», 2. Уфа, Российская Федерация

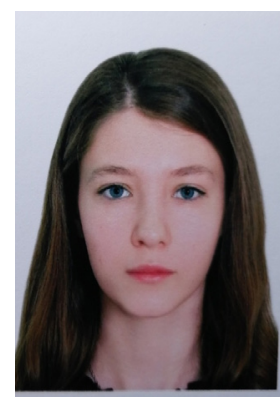

Ахметиина А.И. Akhmetshina A.I.

студент кафедры «Проектный менеджмент и экономика предпринимательства», ФГБОУ ВО «Уфимский государственный нефтяной технический университет», 2. Уфа, Российская Федераиия

DOI: $10.17122 / 2541-8904-2020-1-31-98-104$

\title{
ЭЛЕКТРОННЫЕ АУКЦИОНЫ
} КАК АКТУАЛЬНЫЙ СПОСОБ КОРПОРАТИВНЫХ ЗАКУПОК

В статье рассматриваются актуальные способы проведения корпоративных закупок. Выявлено изменение тренда объема закупок и общей суммы размещенных договоров, осуществляемых организациями, зарегистрированными в единой информационной системе. Проведен анализ способов выбора поставщиков, регламентированных Федеральным законом № 223-Ф3 «О закупках товаров, работ, услуг отдельными видами юридических лиц». Выявлены существенные изменения в структуре способов корпоративных закупок при сохранении преимущества закупок у единственного поставщика. Отмечается необходимость детализации «прочих способов» закупочных процедур с учетом конкретизации закупщиками перечня и порядка их проведения в Положениях о закупках.

По итогам первого полугодия 2019 года, по оценке ЕИС, возросла доля закупок по аукциону. При рассмотрении же абсолютных сумм закупки путем проведения аукциона эти величины сократились на 85-87 \% при сокращении общих объемов закупок на 50 \%. Данное 
обстоятельство подтверждает противоречивость данного способа выбора поставщика. Исследование показало, что традиционные аукционы имеют тенденцию к уменьшению частоты использования, в то время как электронная форма данного способа закупок становится актуальной. Отличительной чертой электронного аукциона является проведение его в Интернете с использованием информационно-коммуникационных технологий на выбранной заказчиком специализированной площадке. В 2019 году корпоративный электронный аукцион проводился на десяти электронных торговых площадках.

Среди преимуществ закупки путем аукциона выделяется выработка требований закупщика по характеристикам закупаемого товара, состязательность по критерию самой низкой закупочной цены; среди недостатков - необходимость проведения экспертизы по завершению договорных отношений, отсутствие партнерских отношений. Передовая закупочная практика предлагает оценивать поставщиков по критерию минимальных совокупных затрат на время действия контракта. Несмотря на существующие риски и проблемы при проведении электронного аукциона, он имеет приоритетность при выборе способа закупок для стандартных товаров.

Ключевые слова: корпоративные закупки, Федеральный закон № 223, способы определения поставщика, конкурентные закупки, партнерские отношения, аукцион, электронный аукцион, электронные торговые площадки.

\section{ELECTRONIC AUCTIONS - THE ACTUAL METHOD OF CORPORATE PROCUREMENT}

The article discusses current methods the corporate procurement. A change in the trend in the volume of procurement and the total amount of hosted contracts carried out by organizations registered in a single information system has been revealed. An analysis is made of the methods for selecting suppliers regulated by Federal Law № 223 “On Procurement of Goods, Works, Services by Certain Types of Legal Entities". Significant changes were revealed in the structure of corporate procurement methods while maintaining the advantage of procurement from a single supplier. The necessity of detailing the "other methods" of procurement taking into account concretization by purchasers of the list and the procedure for procurement implementation in the Procurement Regulations, is noted.

According to the results of the first half of 2019, according to data of the single information system, the share of procurement via auction has increased. When considering the absolute amount of procurement revealed a decrease in the share of procurement via auction by $85-87 \%$ while reducing the total volume of procurement by $50 \%$. This fact confirms the contradictoriness of this method of selecting a supplier. The study showed that traditional auctions tend to decrease in use, while the electronic form of this procurement method becomes relevant. A distinctive feature of the electronic auction is its holding on the Internet with Information and Communication Technologies on the specialized platform selected by the customer. In 2019, a corporate electronic auction was held at ten electronic trading floors.

Among the advantages of procurement through an auction are the development of the requirements for the characteristics of the purchased goods, competitiveness on the lowest purchase price criterion; among the deficiencies - the need for expertise upon completion treaty relations, lack of partnerships. Advanced procurement practice offers evaluating suppliers according to the criterion of minimum total costs for the duration of the contract. Despite the existing risks and problems during the electronic auction, it is a priority when choosing a procurement method for standard goods.

Key words: corporate procurement, Federal Law № 223, ways to identify a supplier, competitive procurement, partnerships, auction, electronic auction, electronic trading floors.

Современная экономика характеризуется созданием единого экономического пространства, достижением гласности и про- зрачности проведения хозяйственных операций на базе общей цифровой платформы [1]. Продажи в цифровом пространстве стано- 
вятся всё более популярным способом закупочных процедур.

Корпоративные закупки направлены на обеспечение предприятий качественными материально-техническими ресурсами в требуемом количестве, в заданное время от надежного поставщика, по выгодной цене. Регулятором взаимодействия участников закупочного процесса является государство. Сфера действия законодательства охватывает вопросы обеспечения условий для развития добросовестной конкуренции, защиты от рисков пользователей поставляемой продукции. Целью исследования является выявление наиболее распространенных способов осуществления корпоративных закупок в рамках действующего законодательства с учетом выработанных критериев.

Основным документом, регламентирующим правила проведения корпоративных закупок, является Федеральный закон № 223Ф3 «О закупках товаров, работ, услуг отдельными видами юридических лиц» (далее Ф3-223), в соответствии с которым закупочная деятельность должна осуществляться конкурентными способами: торговыми (конкурс, аукцион) и неторговыми (запрос предложений, запрос котировок, конкурентные переговоры). Закупки могут осуществляться также у единственного поставщика, то есть неконкурентным способом [2].

Информация о корпоративных закупках размещается в единой информационной системе (далее - ЕИС). Согласно данным ЕИС, с 2017 года наблюдается сокращение объема корпоративных закупок: в 2018 году по сравнению с 2017 годом - на 35 \%, в 2019 году по сравнению с 2018 годом - на 16 \%. За три года объем закупок сократился на 46 \% (рис. 1).

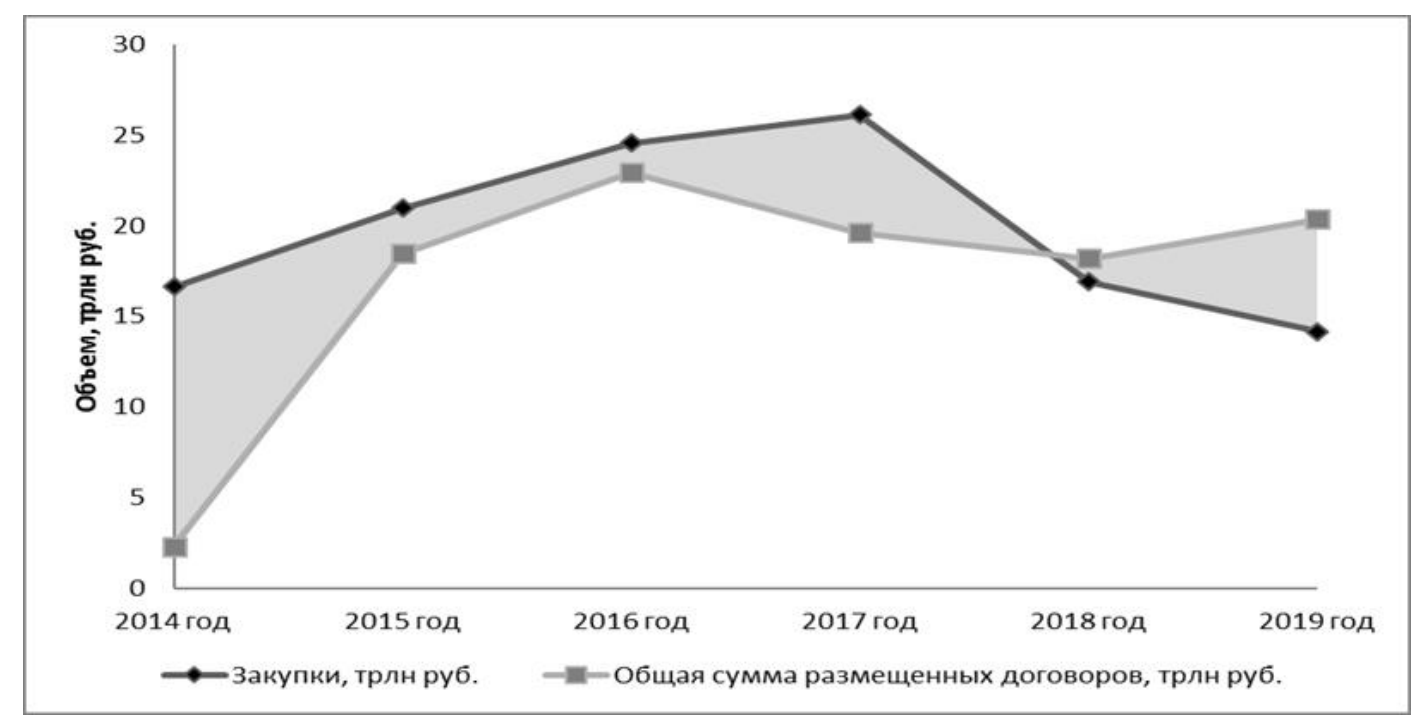

Рисунок 1. Динамика объема закупок и общей суммы размещённых договоров, представленных в ЕИС

С 2018 года объем выполненных закупок по стране становится меньше общей суммы размещенных договоров. Объем закупок по отношению к общей сумме размещенных договоров составил за 2018 год - 92,9 \%, за 2019 год - 69,4\% [3].

По первичным данным мониторинга применения Ф3-223, сохраняется большая доля прямых закупок у единственного поставщика, которая составила в первом полугодии 2019 года 32 \% (на уровне 2017 года). Очень велика доля закупок, осуществляемых компаниями «прочими способами», она достигает 50-60\% [3].

Учитывая, что с 2019 года закупщики конкретизировали в своих положениях о закупках перечень и порядок закупочных процедур в соответствии с законом Ф3-223 (в редакции от 31.12.2017 года), специалистами ЕИС был проведен детализированный выборочный анализ критериев идентификации компаниями способа закупки. Было выявлено, что 
преимущественно «прочие» закупочные процедуры осуществлялись в классической форме конкурентных способов. Доля закупок путем проведения конкурсов составила $22 \%$ от всего количества извещений о закупках, путем проведения аукционов - $13 \%$. По оценке ЕИС, за первое полугодие 2019 года, в сравнении с аналогичным периодом 2018 года, произошло сокращение объемов закупок на 50 \%, в том числе: путем проведения открытого аукциона - на 87 \%; электронного аукциона - на 85 \%; путем проведения открытого конкурса - на $21 \%$ [3].

Доли отдельных способов закупок в соответствии с объемом их извещений в общей совокупности, согласно данным Министерства финансов Российской Федерации, а также их динамика за период 2017-2019 гг. представлены на рисунке 2. Динамика применения различных видов аукционов в 2017-2019 гг. представлена на рисунке 3 .

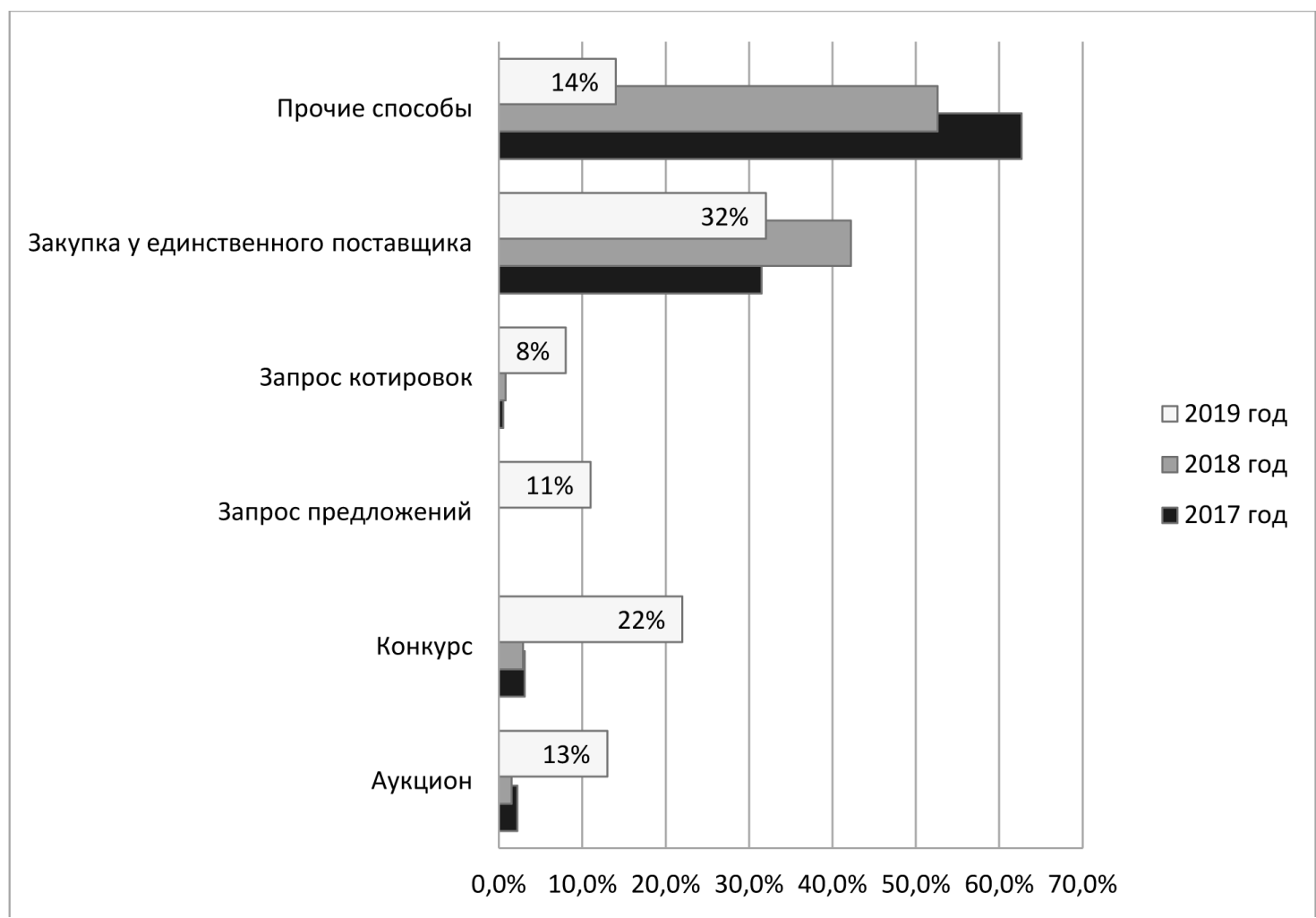

Рисунок 2. Доли отдельных способов закупок в общей совокупности и их динамика за 2017-2019 гг.

Закупки у единственного поставщика способствуют развитию партнерских отношений с конкретным поставщиком при закупке специфичных ресурсов, что позволяет заключать долгосрочные договора [4]. При длительном осуществлении закупок у единственного поставщика исключаются из рассмотрения конкурирующие предложения товаров надлежащего качества по более низким ценам, создаются предпосылки для сговора недобросовестных заказчиков с поставщиками [5].

Конкурс, как способ конкурентных закупок, позволяет выбирать поставщика по нескольким критериям, установленным в пакете конкурсной документации: цена, потребительские свойства, квалификация участника конкурса, сроки, гарантия. Закупки путем проведения конкурсов многообразны: закрытый, открытый, совместный; разноэтапный, с подачей дополнительных ценовых предложений; в электронной форме, в бумажной форме; с ограниченным участием, с предварительным квалификационным отбором; многолотовый, на право заключения договора. 


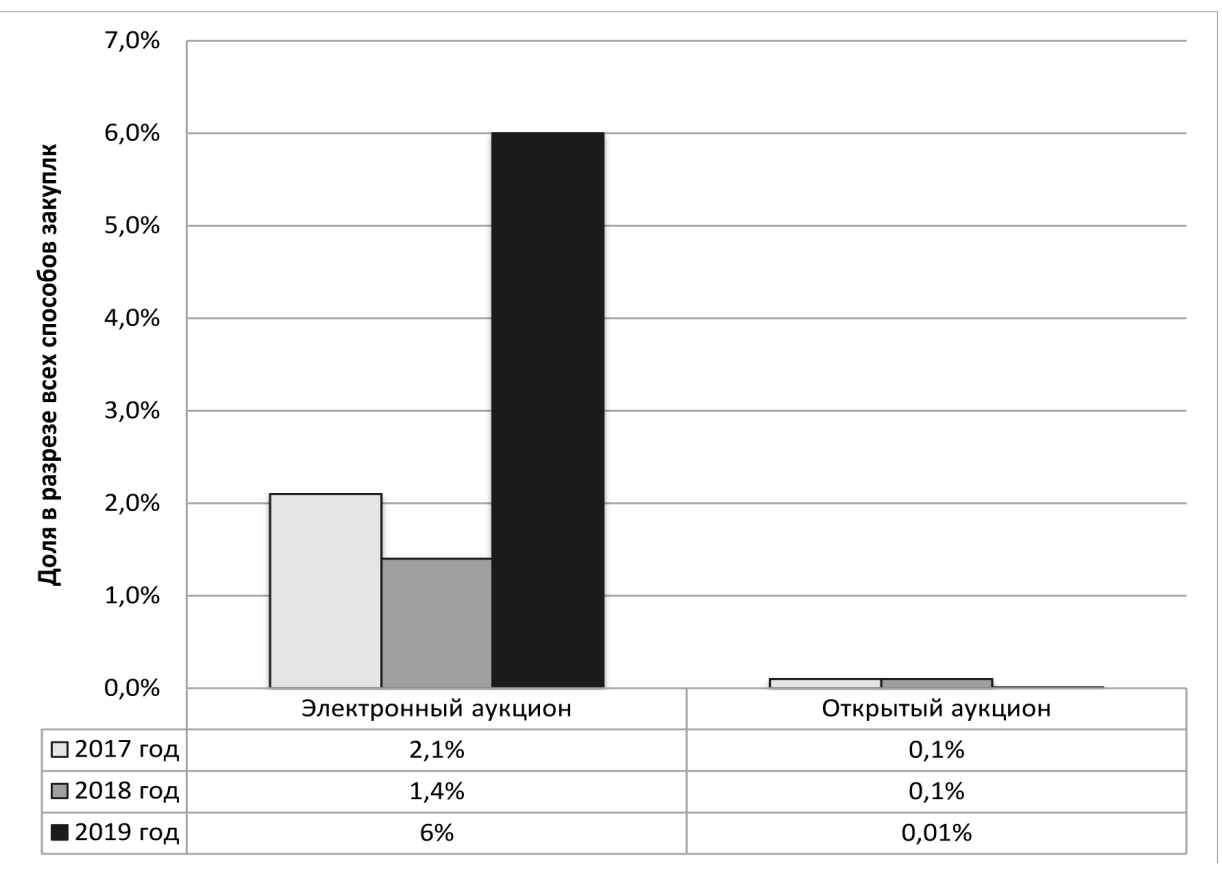

Рисунок 3. Динамика применения различных видов аукционов в 2017-2019 гг. [3]

Закупки по аукциону позволяют компании осуществлять закупки у поставщика по одному критерию - наименьшая цена при полном соответствии поставляемого товара заявленному описанию товара. Формы проведения аукциона также многообразны: закрытый, открытый, совместный, разноэтапный, в электронной форме; с ограниченным участием, заявка с разным количеством частей, на понижение, редукцион.

Электронный аукцион, по определению, характеризуется рядом преимуществ: неограниченное число участников закупки, единые требования ко всем участникам, прозрачность процедуры определения победителя, отсутствие условий для сговора участников посредством обеспечения их конфиденциальности, возможность удаленного участия в закупках, экономия денежных средств вследствие стандартизации процедуры закупок, сокращение риска преднамеренных искажений и ошибок в связи с автоматизацией формирования электронного протокола, полная проверка документации участвующих компаний.

Электронные аукционы являются технически сложным способом проведения закупочной деятельности, для их проведения требуется:
- информационное обеспечение закупочного процесса. Доступ к электронным площадкам требует наличия современной оргтехники, высокой скорости интернет-соединения, рабочих мест для ежедневной работы в сети Интернет и электронного документооборота, что в свою очередь требует значительные финансовые средства;

- кадровое обеспечение закупочного процесса: Специалисты должны знать специальное программное обеспечение, технические системы, нормативную документацию, владеть методиками проведения электронных аукционов, что обуславливает необходимость дополнительного обучения и создания правильной мотивации для специалиста в сфере закупок [6];

- инфраструктурное обеспечение закупочного процесса. Федеральные электронные площадки являются платными, требуют наличия электронной цифровой подписи (что обременительно для местных товаропроизводителей), ограничивают сбыт местных товаропроизводителей. Наличие электронных торговых площадок в регионах будет способствовать сбыту товаров региональных производителей, развитию собственной логистики по способам доставки/получения заказов. Анонимность проведения электронных аук- 
ционов обуславливает непредвиденные расходы за счет географии на доставку приобретенного заказа от подрядчика к закупщику собственными силами или на транспортировку с привлечением логистических компаний.

Данные факторы ограничивают широкое применение электронных аукционов для проведения закупочных процедур, прежде всего предприятиями малого и среднего бизнеса.

Растущее число исследований ставит под сомнение эффективность электронных корпоративных закупок. Электронные аукционы не способствуют развитию партнерских отношений и доверия между поставщиком и покупателем. Сильная привлекательность цены и конкуренции среди участников электронных аукционов нередко приводят к тому, что недобросовестные участники принимают корыстные стратегии, касающиеся сроков доставки и качества товаров и услуг, указанных в публичном конкурсе, для возмещения убытков, понесенных в ходе ценового спора. Для избежания негативных последствий электронных аукционов в мировой практике предлагается формировать аукционную цену на основе минимальных совокупных затрат на закупаемую продукцию с учетом всех затрат, ожидаемых в течение предстоящего срока службы продукта [7, 8].

При закупке, например, промышленной продукции аукционная цена должна дополнительно учитывать затраты на страхование, входной контроль и испытания закупаемой продукции, на рекламации и исправление дефектов при получении бракованной продукции, обслуживание. Минимум совокуп-

\section{Список литературы}

1. Сунаева Г.Г., И.М. Шарипова Институты цифровой экономики проявляются // Наука сегодня: теория и практика: Сборник научных статей. - Уфа: УГУЭС, 2016. - С. 176180.

2. Федеральный закон Российской Федерации «О закупках товаров, работ, услуг отдельными видами юридических лиц» [Электронный ресурс] : от 18.07.2011 № 223Ф3 (ред. от 02.08.2019) // СПС Консультант ных затрат на приобретение аукционного продукта достигается не при минимально достижимой цене покупки, а при минимальных затратах на обслуживание и минимальных рисках.

\section{Выводы}

В ходе исследования выявлены наиболее распространенные способы проведения корпоративных закупок, осуществляемых организациями в единой информационной системе. Наблюдаются структурные изменения в способах закупки. При сохранении преимуществ закупки у единственного поставщика наблюдается увеличение доли электронных конкурсов и аукционов. Наиболее спорным способом закупки считается электронный аукцион. Несмотря на то, что существуют определенные риски и проблемы при осуществлении данного вида закупок, он имеет множество преимуществ, в том числе простоту реализации посредством электронных торговых площадок, что обуславливает некую приоритетность данной процедуры при выборе способа закупок. В процессе подготовки закупочной документации на электронный аукцион специалист должен учитывать множество факторов, влияющих на качество проведения закупки: спрос на закупаемые ресурсы по региону, логистика, сроки годности, затраты на владение продуктом. Предлагается оценивать аукционных поставщиков по критерию минимальных совокупных затрат на время действия контракта. На сегодняшний день электронный аукцион имеет приоритетность при выборе способа закупок для стандартных товаров.

Плюс. URL: http://www.consultant.ru (дата обращения: 20.01.2020).

3. Сайт Министерства Финансов Российской Федерации [Электронный pecypc]. URL: http:// www.minfin.ru. (дата обращения: 21.01.2020).

4. Гареева А.В. Долгосрочные договоры как инструмент повышения эффективности закупочной деятельности предприятий топливно-энергетического комплекса // World 
science: problems and innovations. - 2019. - C. 163-165.

5. Солодилова Н.3., Арапов В.В., Харисов В.И. Анализ институциональной среды внедрения критических технологий субъектами хозяйственной деятельности в регионе // Экономика и управление. - 2014. - № 4 (120). - C. 28-33.

6. Гареева А.В. Необходимый набор компетенций и мотивация персонала при проведении закупочной деятельности // Наука сегодня: теория и практика. - 2019. - С. 60-63.

7. Paulo Ricardo da Costa Reis, Sandro Cabral. Beyond contracted prices: determinants of agility in government electronic procurement // Revista de Administração Pública. 2018. №1. [Электронный ресурс]. URL: http://dx.doi. org/10.1590/0034-7612164442. (дата обращения: 28.01.2020).

8. Sydney Lazarus, Are Reverse Auctions a Threat to Good Supplier Relationships? 2018. [Электронный pecypc]. URL: https:// spendmatters.com/2018/07/12/are-reverseauctions-a-threat-to-good-supplierrelationships/. (дата обращения: 28.01.2020).

\section{References}

1. Sunaeva G.G., Sharipova I.M. Instituti tifrovoj economiki projavljajutca // Nauka sevodnja: teorija i praktika. - Ufa: UGUES, 2016. - P. 176-180.

2. Federal Law of the Russian Federation "On Procurement of Goods, Works, Services by Certain Types of Legal Entities" [Electronic resource]: July 22, 2011 № 223-FL (as amended on August 2, 2019) // ATP Consultant Plus.
URL: http://www.consultant.ru (date of the application: 20.01.2020).

3. Website of the Ministry of Finance of the Russian Federation [Electronic resource]. URL: http:// www.minfin.ru. (date of the application: 21.01.2020).

4. Gareeva A.V. Long-term contract as a tool to improve the efficiency of procurement activities of enterprises fuel and energy complex // World science: problems and innovations. 2019. - P. 163-165.

5. Solodilova N.Z. Arapov V.V., Kharisov V.I. Analiz institutionalnoi sredi vnedrenija kriticheskih tehnologij subektami hozjaistvennoi dejatelnosti v regione // Economika i upravlenie. - 2014. - № 4 (120). - P. 28-33.

6. Gareeva A.V. The necessary set of competencies and staff motivation when conducting procurement activities // Science today: theory and practice // Collection of scientific articles of the V International scientific and practical conference. - Ufa: Ufa State Petroleum Technical University, 2019. - P. 60-63.

7. Paulo Ricardo da Costa Reis, Sandro Cabral. Beyond contracted prices: determinants of agility in government electronic procurement // Revista de Administração Pública. 2018. № 1. [Electronic resource]. URL: http://dx.doi. org/10.1590/0034-7612164442 (date of the application: 28.01.2020).

8. Sydney Lazarus, Are Reverse Auctions a Threat to Good Supplier Relationships? 2018. [Electronic resource].URL: https://spendmatters. com/2018/07/12/are-reverse-auctions-a-threatto-good-supplier-relationships/. (date of the application: 28.01.2020). 